\title{
The ethics of how to manage incidental findings
}

\author{
Carolyn Ells PhD, Brett D. Thombs PhD
}

I

ncidental findings are becoming increasingly common as advanced medical technologies are used in research and clinical care. These potentially relevant findings fall outside the primary purpose for conducting a test or procedure. Incidental findings may be anticipated (known to be potentially associated with the test) or unanticipated (not typically associated). Secondary findings are actively sought but not the primary reason for testing.

In Canada, there is relatively little formal ethical guidance to help clinicians and researchers determine their obligations and responsibilities regarding incidental findings, including when it is ethically responsible or required to disclose such findings to patients. Guidance documents for clinicians usually mention the issue only briefly or not at all. Even the latest edition of the Tri-Council Policy Statement, Canada's main ethical guideline concerning research involving humans, has less than half a page on the topic. ${ }^{1}$ In the United States, the Presidential Commission for the Study of Bioethical Issues recently issued a 146-page report, "Anticipate and Communicate: Ethical Management of Incidental and Secondary Findings in the Clinical, Research, and Direct-to-Consumer Contexts," ${ }^{2}$ which will be a useful resource for Canadian physicians and researchers who must make increasingly complex decisions around managing incidental findings. The report describes key considerations that inform management of incidental findings in an excellent analysis of evidence and 17 general and context-specific recommendations.

One important consideration is the potential for either beneficial or harmful consequences to arise for patients and research participants when incidental findings are disclosed and further investigated. Discovery of a life-threatening tumour while imaging a participant in a research study may lead to life-saving surgery that removes the tumour. Conversely, acting on the discovery of an unusual mass found in a research context could lead to burdensome diagnostic workups or follow-ups, harms from medical procedures, anxiety and unnecessary costs, without corresponding benefit to the patient. Since the 1960s, when mammography was first tested in a randomized controlled trial, there has been great enthusiasm for the idea that information from medical tests can prevent disease and reduce mortality. ${ }^{3}$ A great number of screening tests are now promoted, with the accompanying imperative to act on incidental findings, which may or may not benefit patients, but can harm them. The increasing realization that screening, although potentially beneficial, is not always benign has led to guidelines calling for more restricted use of tests for detecting breast ${ }^{4}$ and colon cancer, ${ }^{5}$ for instance.

Thus, although it may be tempting to alert a patient to findings discovered incidentally during a clinical test or imaging for research purposes, the US commission cautions that a careful analysis of potential benefits versus potential harms and their relative importance to patients should precede disclosure and that ideally this course of action should be determined "before the fact" if incidental findings can be anticipated. Specifically, it urges that, before testing, physicians and researchers (a) describe to the person to be tested the anticipated incidental findings that may arise, (b) have a plan in place to deal with any findings that do arise and (c) disclose that plan to the person to be tested. These recommendations are supported by the ethical principles of respect for persons, beneficence, justice and fairness, and intellectual freedom and responsibility.

How should a clinician or researcher make such a plan and determine when to disclose incidental results? A careful evaluation of potential benefits and harms should underpin the process. Practice standards or guidelines may be available to inform this decision, but this is not always the case. The US commission recommends that professional representative groups develop guide-

\section{KEY POINTS}

- Acting on findings discovered incidentally during clinical tests or imaging for research purposes can have beneficial or harmful consequences for patients.

- Clinicians and researchers should anticipate and plan for incidental findings.

- Evidence-based best practices are needed to guide decisions regarding disclosure of incidental findings.

- Patients' preferences about disclosure of incidental findings should be taken into account.
Competing interests: None declared.

This article was solicited and has not been peer reviewed.

Correspondence to: Carolyn Ells, carolyn.ells @mcgill.ca

CMAJ 2014. DOI:10.1503 /cmaj.140136 
lines on evidence-based best practices for managing incidental and secondary findings. Unfortunately, in many situations where such findings arise currently, evidence is inadequate to be readily applied. Research is needed to characterize "the types and frequency of findings that can arise from various modalities; the potential costs, benefits, and harms of identifying, disclosing, and managing these findings; and the recipient and practitioner preferences about the discovery, disclosure, and management of incidental and secondary findings," and to determine the costeffectiveness of tests and procedures that generate incidental findings. ${ }^{2}$ The commission also recommends that professional and public health organizations "produce evidence-based standards for proposed screening programs that take into account the likelihood that incidental findings will arise."

In the absence of clear evidence or when faced with unanticipated incidental findings of potential concern, researchers are advised to consult qualified experts to assess the importance of the finding and plan a response. ${ }^{2}$ This is slightly stronger guidance than in Canada's Tri-Council Policy Statement, which advises researchers to "consult with colleagues or refer to standards within the discipline" if uncertain whether findings are material, and to consult their research ethics board or colleagues about possible disclosure. ${ }^{1}$ It is reasonable to assume that, in directing researchers to colleagues for consultation, the intent is to determine the standards within the discipline, perhaps combined with the practical wisdom of a consultant who is knowledgeable and experienced in this clinical area. Regardless of the source of consultation (e.g., practice guidelines or experts), the guidance should be based on the best evidence available, whether making decisions in clinical or research settings.

One important concern is not well described in the US commission's report: the incorporation of patients' preferences into decision-making regarding disclosure of incidental findings. Just as physicians may overestimate the potential benefits of testing and underestimate the potential harms, ${ }^{6}$ patients may have unrealistic expectations about the benefits of test results and are not typically aware that disclosure of results may actually be harmful. ${ }^{7-9}$ Patients' preferences about disclosure of incidental findings may not align with what is known about the benefits of disclosure. However, it is important that plans for disclosure attempt to account for both evidence and what patients prefer. When evidence is clear regarding benefit versus harm, the plan about whether or not findings will be disclosed could simply be described to patients when obtaining their consent for testing. However, when evidence is not clear, planning will need to include provisions for describing potential benefits and risks to patients and helping them make decisions that incorporate their own values and preferences. ${ }^{10}$

\section{References}

1. Tri-Council Policy Statement: ethical conduct for research involving humans. Ottawa $(\mathrm{ON})$ : Canadian Institutes of Health Research, Natural Sciences and Engineering Research Council of Canada, Social Sciences and Humanities Research Council of Canada; 2010. Available: www.pre.ethics.gc.ca/eng/policy-politique /initiatives/tcps2-eptc2/Default/ (accessed 2014 Jan. 30).

2. Anticipate and communicate: ethical management of incidental and secondary findings in clinical, research, and direct-toconsumer contexts. Washington (DC): Presidential Commission for the Study of Bioethical Issues; 2013. Available: http://bioethics .gov/node/3183 (accessed 2014 Jan. 30).

3. Black WC, Welch HG. Screening for disease. AJR Am J Roentgenol 1997;168:3-11.

4. Tonelli M, Connor Gorber S, Joffres M, et al.; Canadian Task Force on Preventive Health Care. Recommendations on screening for breast cancer in average-risk women aged 40-74 years. CMAJ 2011;183:1991-2001.

5. Moyer VA; US Preventive Services Task Force. Screening for prostate cancer: US Preventive Services Task Force recommendation statement. Ann Intern Med 2012;157:120-34.

6. Woolf SH. The price of false beliefs: unrealistic expectations as a contributor to the health care crisis. Ann Fam Med 2012;10:491-4.

7. Herndon MB, Schwartz LM, Woloshin S, et al. Older patients perceptions of "unnecessary" tests and referrals: a national survey of Medicare beneficiaries. J Gen Intern Med 2008;23:1547-54.

8. Schwartz LM, Woloshin S, Sox HC, et al. US women's attitudes to false positive mammography results and detection of ductal carcinoma in situ: cross sectional survey. BMJ 2000;320: 1635-40.

9. Schwartz LM, Woloshin S, Fowler FJ Jr, et al. Enthusiasm for cancer screening in the United States. JAMA 2004;291:71-8.

10. Montori VM, Brito JP, Murad MH. The optimal practice of evidence-based medicine incorporating patient preferences in practice guidelines. JAMA 2013;310:2503-4.

Affiliations: Departments of Medicine (Ells) and Psychiatry (Thombs), McGill University; Lady Davis Institute for Medical Research (Ells, Thombs), Montréal, Que.

Contributors: Both authors contributed substantially to the writing and critical revision of the manuscript, approved the final version submitted for publication and agreed to act as guarantors of the work. 